\title{
Olumluluğun Biçimsel Dillerdeki Sembolik Gösteriminde Bulanık Mantık Yaklaşımı
}

\author{
Özge Sinem İmrăg
}

https://dx.doi.org/10.37583/diyalog.802193

\section{$\ddot{o}_{z}$}

Türkçe, Almanca, İngilizce gibi doğal dillerde bir tümce temelde özne ve yüklemden oluşur. Benzer şekilde biçimsel dillerde de bir tümce, yüklem ve argümandan oluşur. Yüklemler $\mathrm{P}, \mathrm{Q}, \mathrm{R}$ gibi büyük harflerle, argümanlar ise $x, y, z$ gibi küçük harflerle gösterilir. Örneğin olumlu bir tümce $\mathrm{P}(\mathrm{x})$, olumsuz bir tümce ise $-\mathrm{P}(\mathrm{x})$ şeklinde ifade edilebilir. Ancak bazen bir tümcenin olumlu mu yoksa olumsuz mu olduğu net bir şekilde belli olmayabilir. Bu tür durumlarda mevcut sembolik gösterimde belirsizlikler ortaya çıkabilmektedir. Olumlu tümcelere matematiksel olarak 1, olumsuz tümcelere ise 0 değerinin verildiği varsayılırsa, olumluluk veya olumsuzluk durumu belirsiz olan tümceler ancak bu iki değer arasında bir değer alabilir. Diğer bir deyişle $\mathrm{P}(\mathrm{x})$ şeklinde gösterilebilen bir tümceyi $\mathrm{P}_{1}(\mathrm{x}),-\mathrm{P}(\mathrm{x})$ şeklinde gösterilen bir tümceyi ise $\mathrm{P}_{0}(\mathrm{x})$ şeklinde ifade etmek mümkündür; fakat olumluluğu kesin olmayan tümceler bu değerlerle gösterilemeyeceği için başka bir ifade şekline ihtiyaç vardır. Çünkü bu tümcelerdeki iş, oluş veya hareketin gerçekleşme oranı ne 0 ne de 1'dir; 0 ve 1 arasında bir değerdir. Bu çalışmada bu tür tümcelerin biçimsel dillerde nasıl ifade edilebileceğine dair bir öneride bulunmak ve bulanık küme kuramıyla olumluluğu derecelendirmek amaçlanmıştır. Bu amaç doğrultusunda önerilen yaklaşım birtakım örnek tümceler üzerinde uygulanmış ve söz konusu tümceler bulanık sembolik bir gösterimle ifade edilmiştir.

Anahtar Sözcükler: biçimsel diller, olumluluk, belirsizlik, bulanık küme kuramı, matematiksel dilbilim.

\section{Abstract \\ A Fuzzy Logic Approach for Symbolic Representation of Affirmativeness in Formal Languages}

In natural languages such as Turkish, German and English, a sentence consists essentially of a subject and predicate. Similarly, in formal languages, a sentence consists of a predicate and an argument. The predicates are shown in capital letters such as $\mathrm{P}, \mathrm{Q}, \mathrm{R}$, and arguments in small letters such as $\mathrm{x}, \mathrm{y}$, z. For example, an affirmative sentence can be expressed as $\mathrm{P}(\mathrm{x})$ and a negative sentence as $-\mathrm{P}(\mathrm{x})$. However, sometimes it is not clear whether a sentence is affirmative or negative. In such cases, uncertainties may arise in the present symbolic representation. Assuming that affirmative sentences are given a mathematical value of 1 and negative sentences are given a value of 0 , sentences with an uncertain status of affirmative or negative can only take a value between these two values. In other words, it is possible to express a sentence that can be represented as $\mathrm{P}(\mathrm{x})$ as $\mathrm{P}_{1}(\mathrm{x})$, and a sentence that is shown as $-\mathrm{P}(\mathrm{x})$ as $\mathrm{P}_{0}(\mathrm{x})$. However, since the sentences whose affirmativeness is not certain cannot be represented by these values, another form of expression is needed. Because the realisation ratio of action, state or occurrence in these sentences is neither 0 nor 1 , it is a value between 0 and 1 . In this study, it is aimed to make a suggestion

Einsendedatum: 26.05.2020

Freigabe zur Veröffentlichung: 30.09.2020 
about how such sentences can be expressed in formal languages and to evaluate affirmativeness with fuzzy set theory. For this purpose, the proposed approach was applied on a number of example sentences and these sentences were expressed in a fuzzy symbolic representation.

Keywords: Formal languages, affirmativeness, vagueness, fuzzy set theory, mathematical linguistics. 


\section{EXTENDED ABSTRACT}

In natural languages, a sentence consists essentially of a subject and predicate. Similarly, in formal languages, a sentence consists of a predicate and arguments. The predicates are shown in capital letters such as P, Q and arguments in small letters such as $\mathrm{x}, \mathrm{y}$. For example, an affirmative sentence can be expressed as $\mathrm{P}(\mathrm{x})$ and a negative sentence as $-\mathrm{P}(\mathrm{x})$. Sometimes it is not clear whether a sentence is affirmative or negative and therefore uncertainties may arise in the present symbolic representation of affirmativeness in formal languages. Assuming that affirmative sentences are given a mathematical value of 1 and negative sentences 0 , sentences with an uncertain status of affirmative or negative can only take a value between these two values. However, since the sentences, whose affirmativeness is not certain, cannot be represented by these values, another form of expression is needed. In this study, it is aimed to make a suggestion about how such sentences can be expressed in formal languages.

For this aim, a new approach was proposed to express fuzzy predicates in formal languages with minimum uncertainty. The proposed approach was applied on some sentences. In this approach, the sigmoid membership function was used to find the membership degrees of the sentences. For this purpose, 15 sentences were scored one to five by 10 participants according to the degree of affirmativeness. The sigmoid function is an "S" -shaped function that converts any input value between $\infty$ and $-\infty$ to a value between 0 and 1 . This function is shown as follows:

$$
\mu(x)=\frac{1}{1+e^{-a(x-c)}}
$$

Here, $a$ is the slope parameter of the function, $x$ is the input value, and $c$ is the $x$ value in the middle of Sigmoid. In this study, the input value (x) was taken as the mean of the scores given to the sentences by the experts. Since the mean value of the scores 1 to 5 is 3 , the parameter $c$ was taken as 3 and the value of $a$ is calculated as 2 , which brings the value of the function closer to 1 when $x$ is at the maximum $(\mathrm{x}=5)$ and closer to 0 when it is minimum $(\mathrm{x}=0)$.

The sentences examined by experts and the scores given to these sentences are as follows:

\begin{tabular}{lccccccccccccc}
\hline \multirow{2}{*}{ Sentences } & \multicolumn{1}{c}{ Scores given by experts } & \multicolumn{1}{c}{ Average } \\
\cline { 2 - 13 } & E1 & E2 & E3 & E4 & E5 & E6 & E7 & E8 & E9 & E10 & \\
\hline Çocuk uyudu. & 5 & 5 & 5 & 5 & 5 & 5 & 5 & 5 & 5 & 5 & 5 \\
Çocuk uyumad1. & 1 & 1 & 1 & 1 & 1 & 1 & 1 & 1 & 1 & 1 & 1 \\
Çocuk uyumak üzere. & 4 & 3 & 4 & 2 & 4 & 4 & 4 & 4 & 4 & 4 & 3,9 \\
Çocuk uyuyacak gibi. & 3 & 1 & 2 & 4 & 3 & 3 & 3 & 3 & 3 & 2 & 2,5 \\
Çocuk neredeyse & 4 & 4 & 3 & 3 & 4 & 4 & 4 & 2 & 4 & 3 & 3,5 \\
\hline
\end{tabular}


uyuyacak.

\begin{tabular}{lccccccccccc}
\hline Yağmur yağmıyor. & 1 & 1 & 1 & 1 & 1 & 1 & 1 & 1 & 1 & 1 & 1 \\
Yağmur yağdı yağacak. & 4 & 4 & 3 & 4 & 2 & 4 & 4 & 2 & 4 & 4 & 3,5 \\
Yağmur yağmak üzere. & 4 & 3 & 3 & 3 & 2 & 4 & 3 & 4 & 3 & 3 & 3,2 \\
Yağmur yağacak gibi. & 3 & 1 & 2 & 2 & 2 & 3 & 3 & 3 & 2 & 2 & 2,3 \\
Yağmur yağıyor. & 5 & 5 & 5 & 5 & 5 & 5 & 5 & 5 & 5 & 5 & 5 \\
\hline & & & & & & & & & & & \\
\hline Film iyi gibi. & 3 & 3 & 3 & 4 & 4 & 3 & 3 & 2 & 4 & 2 & 3,1 \\
Film iyi. & 5 & 5 & 5 & 5 & 5 & 5 & 5 & 5 & 5 & 5 & 5 \\
Film iyi sayılır. & 4 & 4 & 3 & 3 & 4 & 3 & 4 & 4 & 4 & 4 & 3,7 \\
Film kötü. & 1 & 1 & 1 & 1 & 1 & 1 & 1 & 1 & 1 & 1 & 1 \\
Film fena sayılmaz. & 4 & 2 & 3 & 2 & 3 & 3 & 2 & 3 & 3 & 3 & 2,8 \\
\hline
\end{tabular}

By using the mean scores obtained for each sentence, the membership degrees of sentences in the "affirmative" set were calculated. For example, the membership degree of the third sentence is calculated as follows:

$\mu(x)=\frac{1}{1+\mathrm{e}^{-\mathrm{a}(x-\mathrm{c})}}=\frac{1}{1+\mathrm{e}^{-2(3,85-3)}}=0,85$

Therefore, the membership degree in the "affirmative" set of this sentence is found as 0.85 and it can be represented symbolically as $\mathrm{P}_{0.85}(\mathrm{x})$. Membership degrees and symbolic representations of other sentences are as follows.

\begin{tabular}{lcc}
\hline Sentences & $\mu_{\text {affirmative }}$ & $\begin{array}{c}\text { Fuzzy Symbolic } \\
\text { Representation }\end{array}$ \\
\hline Çocuk uyudu. & 0,98 & $\mathrm{P}_{0,98}(\mathrm{x})$ \\
Çocuk uyumadı. & 0,02 & $\mathrm{P}_{0,02}(\mathrm{x})$ \\
Çocuk uyumak üzere. & 0,85 & $\mathrm{P}_{0,85}(\mathrm{x})$ \\
Çocuk uyuyacak gibi. & 0,27 & $\mathrm{P}_{0,27}(\mathrm{x})$ \\
Çocuk neredeyse uyuyacak. & 0,73 & $\mathrm{P}_{0,73}(\mathrm{x})$ \\
\hline & & \\
\hline Yağmur yağmıyor. & 0,02 & $\mathrm{P}_{0,02}(\mathrm{x})$ \\
Yağmur yağdı yağacak. & 0,73 & $\mathrm{P}_{0,73}(\mathrm{x})$ \\
Yağmur yağmak üzere. & 0,60 & $\mathrm{P}_{0,60}(\mathrm{x})$ \\
Yağmur yağacak gibi. & 0,20 & $\mathrm{P}_{0,20}(\mathrm{x})$ \\
Yağmur yağıyor. & 0,98 & $\mathrm{P}_{0,98}(\mathrm{x})$ \\
\hline & & \\
\hline Film iyi gibi. & 0,55 & $\mathrm{P}_{0,55}(\mathrm{x})$ \\
Film iyi. & 0,98 & $\mathrm{P}_{0,98}(\mathrm{x})$
\end{tabular}




$\begin{array}{lll}\text { Film iyi sayılır. } & 0,80 & \mathrm{P}_{0,80}(\mathrm{x}) \\ \text { Film kötü. } & 0,02 & \mathrm{P}_{0,02}(\mathrm{x}) \\ \text { Film fena sayılmaz. } & 0,40 & \mathrm{P}_{0,40}(\mathrm{x})\end{array}$

In this paper, only symbolic representation such as $\mathrm{P}(\mathrm{x})$ was taken into account, but there are different representation forms in formal languages. This study should be considered as a first step in this direction and it is recommended to consider other representation forms in following studies. 


\section{Giriş}

İnsanı diğer bütün canlılardan ayıran dil, yalnızca insanlar arasındaki iletişimi değil, her geçen gün artan teknolojik gelişmeler sayesinde artık insanlarla makineler arasında ve hatta makinelerle diğer makineler arasında iletişimi sağlayan unsurdur. İnsanlar arasındaki iletişim Türkçe, Almanca, İngilizce, Çince gibi doğal diller yoluyla gerçekleşirken, makinelerle olan iletişim biçimsel diller vasıtasıyla gerçekleşmektedir.

Doğal dillerde birden fazla anlam taşıyan ifadeler bulunmakta ve bu tür ifadeler birden fazla şekilde yorumlanacağı için bazı belirsizliklere yol açabilmektedir. Örneğin "vahşi hayvan bakıcısı" ifadesinde "vahşi" sözcüğü bir yoruma göre "hayvanı" başka bir yoruma göre ise "hayvan bakıcısını" niteleyebilir (bkz. Hodges 1988: 77). Bu tür belirsizliklere yol açması nedeniyle doğal diller, elektronik aletlerin kullanma talimatlarındaki gibi oldukça sınırlandırılmış bir biçimde olmadığı sürece bilgisayarların çözmesi gereken durumlarda kullanıma pek elverişli değildir. Böyle durumlar için nispeten az sayıda sentaktik kural yardımıyla, bilgisayarların kapsamlı bir biçimde anlayabileceği bir semantik sunan programlama dilleri gibi biçimsel diller daha uygundur (bkz. Hedstück 2012: 5). Kısacası biçimsel diller, doğal dillerde karşılaşılabilecek bazı belirsizlikleri daha net ifade etmeye yarar.

Herhangi bir doğal dilde tümce, bir ad öbeği ve bir eylem öbeğinden oluşur. Ad öbeği tümcede özne görevini üstlenir ve tümcedeki iş, oluş veya hareketin ne olduğunu ya da bunu kimin yaptığını bildirir. Eylem öbeği tümcede iş, oluş, hareket bildiren yüklem görevini üstlenir. Yüklemin en önemli özelliği cümleyi bir yargıyla sonuca bağlamasıdır. Bu nedenle yüklem cümlenin temel ögesidir (Hengirmen 2007: 322).

Türkçe, İngilizce ve Almanca gibi doğal dillerde bir tümcenin temelde bir özne ve bir yüklemden oluşmasına benzer bir şekilde biçimsel dillerde de bir tümce yine yüklem ve argümandan oluşur. Argümanların sahip olduğu özellikler yüklemlerdir. Yüklemler $\mathrm{P}, \mathrm{Q}, \mathrm{R}$ gibi büyük harflerle, argümanlar ise $\mathrm{x}, \mathrm{y}, \mathrm{z}$ gibi küçük harflerle gösterilir. Örneğin; Kuşlar yerine $\mathrm{x}$, serçe yerine $\mathrm{y}$, uçabilir yerine $\mathrm{P}$, küçüktür yerine Q kullanıldığı varsayılırsa, Kuşlar uçabilir tümcesi $\mathrm{P}(\mathrm{x})$ şeklinde, Serçe küçüktür tümcesi ise $\mathrm{Q}(\mathrm{y})$ şeklinde ifade edilir. Bir tümce olumlu olabildiği gibi olumsuz da olabilir. Olumluluk ve olumsuzluk tümcelerin temel anlam özelliğidir (bkz. Karahan 2015: 103). Börekçi (2003), olumluluk ve olumsuzluk konusunda şu açıklamalarda bulunur:

Geleneksel dil bilgisinde "biçimce" diye adlandırılan olumluluk, fiil cümlelerinde eylemin veya oluşun gerçekleştiğini (kılma); isim cümlelerinde de durumun olduğunu, onaylandığını veya nesnenin var olduğunu (olma) belirtmektedir. Olumsuzluk ise eylemin gerçekleşmediğini (kılmama); durumun olmadığını, reddedildiğini veya nesnenin var olmadığını (olmama) belirtmektedir. (Börekçi 2003: 52)

Olumsuz tümceler biçimsel bir dilde ifade edilirken $\mathrm{P}(\mathrm{x})$ ya da $\mathrm{Q}(\mathrm{y})$ gibi ifadelerin başına eksi işareti getirilir. Örneğin $\mathrm{P}(\mathrm{x})$ yerine $-\mathrm{P}(\mathrm{x})$ veya $\mathrm{Q}(\mathrm{y})$ yerine $-\mathrm{Q}(\mathrm{y})$ ifadeleri kullanılır. $\mathrm{P}(\mathrm{x})$ ifadesi "P eylemini yapan bir $\mathrm{x}$ vardır" ya da " $\mathrm{x}, \mathrm{P}$ eylemini yapar" anlamına gelmektedir. Aynı şekilde $-\mathrm{P}(\mathrm{x})$ de "P eylemini yapan bir $\mathrm{x}$ yoktur" ya da " $\mathrm{x}$, $\mathrm{P}$ eylemini yapmaz" anlamına gelmektedir. 
Doğal dillerde bir tümce her zaman tamamen olumlu ya da tamamen olumsuz olmayabilir. Başka bir deyişle bazen bir tümcenin olumluluk veya olumsuzluk durumu çok net anlaşılmayabilir. Örneğin "Çocuk uyumak üzereydi” gibi bir tümce ele alınacak olursa, çocuğun uyuma eylemine çok yaklaştığı, fakat henüz uyumadığı görülür. "Dersimiz bitti gibi" tümcesinden de dersin henüz bitmediği ama bitmesine az kaldığ sonucu çıkmaktadır. İmrağ (2018: 63-65) tümcelerdeki bu tür olumsuzluğu bulanık olumsuzluk olarak terimlendirmiştir. Yazar, "gibi” ve "üzere” edatlarının, "neredeyse", "az kalsın", "az daha” gibi bazı zarfların ve "sayılmak" eyleminin tümcelerde bulanık olumsuzluk oluşturduğunu ifade etmiştir.

Terricabras (2015) ise olumluluğun net olmadığı yüklemleri bulanık yüklem olarak tanımlamıştır. Ona göre bulanık yüklem, 0 ile 1 arasında sonsuz olarak bölünebilen bir aralığı açar. Bulanık yüklemler eğer doğru bir şekilde nicelenirlerse matematiksel olarak ifade edilebilirler (Terricabras 2015: 24).

Biçimsel dillerde olumlu yükleme sahip tümceler $\mathrm{P}(\mathrm{x})$, olumsuz yükleme sahip tümceler ise $-\mathrm{P}(\mathrm{x})$ şeklinde ifade edildiğine göre, bulanık yükleme sahip tümceler için farklı bir gösterim gerektiği görülmektedir; çünkü bulanık yüklemlerde iş, oluş, hareket ne kesin olarak gerçekleşmiş ne de kesin olarak gerçekleşmemiştir. Bu noktada matematiksel bir gösterim şekline ihtiyaç vardır.

Olumlu tümcelere matematiksel olarak 1 , olumsuz tümcelere ise 0 değerinin verildiği varsayılırsa, "Çocuk uyudu" tümcesi 1, "Çocuk uyumadı" tümcesi 0 değerini alır. "Çocuk uyumak üzereydi" tümcesi ise ancak bu iki değer arasında bir değer alabilir. Diğer bir deyişle $\mathrm{P}(\mathrm{x})$ şeklinde gösterilebilen bir tümcenin değeri 1 olur ve $\mathrm{P}_{1}(\mathrm{x})$ şeklinde ifade edilebilir. $\mathrm{Bu}$, " $\mathrm{x}, \mathrm{P}$ eylemini gerçekleştirdi” anlamına gelir. -P(x) şeklinde gösterilen bir tümcenin değeri ise 0 olur ve $\mathrm{P}_{0}(\mathrm{x})$ şeklinde ifade edilebilir. $\mathrm{Bu}$ da "x, P eylemini gerçekleştirmedi" anlamına gelir. Fakat bulanık yükleme sahip tümceler bu değerlerle gösterilemeyeceği için başka bir ifade şekline ihtiyaç vardır; çünkü bu tümcelerdeki iş, oluş veya hareketin gerçekleşme oranı ne 0 ne de 1 'dir. 0 ve 1 arasında bir oranda gerçekleşmiştir. Yani örneğin "x, $P$ eylemini 0,40 oranında gerçekleştirdi” ya da "x, P eylemini 0,90 oranında gerçekleştirdi" anlamına gelen bir sembolik gösterim gerekmektedir. Bulanık küme kuramı - veya bulanık mantık - bu noktada bir çözüm sunmaktadır. Çünkü bulanık mantık, doğru bir şekilde nicelendirilmeleri durumunda, bulanık yüklemlerin matematiksel kesinlik ile incelenebilecek olduğunu kanıtlamaya çalışır (Terricabras 2015: 24). Bu çalışmada bulanık yüklemlerin biçimsel dillerde minimum belirsizlikle ifade edilebilmesi için yeni bir yaklaşım önerilmiştir. Önerilen yaklaşım birtakım örnek tümceler üzerinde uygulanmış ve söz konusu tümceler bulanık sembolik bir gösterimle ifade edilmiştir.

\section{Biçimsel Dillerdeki Sembolik Gösterimin Bulanıklaştırılması}

Bulanık küme kuramı ilk defa 1965 yılında Lotfi A. Zadeh tarafından ortaya konulmuştur. İnsan mantığı, açık, kapalı, sıcak, soğuk, 0 ve 1 gibi değişkenlerden oluşan kesin ifadelerin yanı sıra, az açık, az kapalı, serin, 1lık gibi ara değerleri de göz 
önüne almaktadır (Elmas 2016: 204). Bütün bu ara değerler bulanık ifadelerdir ve klasik küme kuramına göre ifade edilmeleri zordur.

\begin{abstract}
Klasik küme kuramında, bir kümeye giren elemanların oraya ait olmaları durumunda üyelik dereceleri 1'e, ait olmamaları durumunda ise 0'a eşit kabul edilir ve bu ikisinin arasında hiçbir üyelik derecesi düşünülemez. Bulanık küme kuramında ise 0 ile 1 arasında değişen üyelik derecelerinden söz etmek mümkündür. (Toksöz ve Yılmaz 2019: 3)
\end{abstract}

Biçimsel dillerdeki sembolik gösterim yakından incelenirse mevcut gösterimin klasik küme kuramını yansıttığı görülmektedir. "Olumlu” ve "olumsuz" olmak üzere iki kümenin var olduğu düşünülürse, klasik küme kuramına göre, bir tümce ya tamamen "olumlu" kümesine ya da tamamen "olumsuz" kümesine aittir. Başka bir ifadeyle, bir tümcenin üyelik derecesi ya 0 ya da 1 'dir. Örneğin, "Patron geldi” tümcesinde patron yerine $\mathrm{x}$, geldi yerine $\mathrm{P}$ kullanıldığ $\mathrm{Bu}$, söz konusu tümcenin 1 üyelik derecesiyle "olumlu" kümesine ait olduğu anlamına gelir. Bu tümce "Patron gelmek üzere" şeklinde yazılacak olursa klasik sembolik gösterime göre yine $\mathrm{P}(\mathrm{x})$ ile gösterilir ve yine 1 üyelik derecesiyle olumlu kümesine ait olur. Buna karşın, bulanık küme kuramına göre, bir tümcenin "olumlu" ya da "olumsuz" kümesine ait olma derecesi 0 ve 1 arasında değişmelidir. Yine "patron gelmek üzere" tümcesi göz önüne alınacak olursa, bulanık küme kuramına göre bu tümce 0 ve 1 arasında değişen üyelik derecesiyle "olumlu" ya da "olumsuz" kümesine ait olur. Diğer bir ifade ile ne tamamen olumlu ne de tamamen olumsuz olur. Dolayssiyla bu tür ifadelerin $\mathrm{P}(\mathrm{x})$ veya $-\mathrm{P}(\mathrm{x})$ şeklinde gösterilmesindense, ne derece olumlu olduklarını belirtmek amacıyla $\mathrm{P}_{0.2}(\mathrm{x}), \mathrm{P}_{0.5}(\mathrm{x}), \mathrm{P}_{0.8}(\mathrm{x})$ vb. şekilde gösterilmesi daha doğru olabilir.

\title{
Bulanıklaştırma Süreci
}

$\mathrm{Bu}$ çalışmada önerilen bulanık mantık yaklaşımında, tümcelerin "olumlu" ya da "olumsuz" kümesine olan üyelik derecelerinin bulunması amaciyla sigmoid üyelik fonksiyonundan yararlanılmıştır. Bu amaçla ilk olarak 15 değişik tümce hazırlanmış ve bu tümceler 10 adet katılımcı tarafından 1 ile 5 aralığında olmak üzere olumluluk derecesine göre puanlandırılmıştır. Olumluluk puan dereceleri Tablo 1'de, örnek tümceler ve uzmanlar tarafından verilen puanlar ise Tablo 2'de verilmiştir. Katılımcılar Sivas Cumhuriyet Üniversitesi, Edebiyat Fakültesi, Türk Dili ve Edebiyat1, Alman Dili ve Edebiyat1, İngiliz Dili ve Edebiyat1, Fransız Dili ve Edebiyat1, MütercimTercümanlık Bölümlerinde akademisyen olarak çalışmaktadırlar. Dolayısıyla, uygulamaya dâhil edilen katılımcıların dil alanında deneyim sahibi, diğer bir deyişle dil alanında uzman kişiler arasından seçilmesine dikkat edilmiştir. Ayrıca, katılımcıların dil alanında deneyim sahibi olmalarından dolayı 10 katılımcının yeterli olacağ düşünülmüştür. Ancak bu sayı tümcelerin karmaşıklığına göre arttırılabilir.

Örnek tümceler hazırlanırken İmrağ (2018: 63-65) tarafından bulanık olumsuzluk oluşturdukları öne sürülen "sayılmak" eyleminin, "gibi”, “üzere" edatlarının ve "neredeyse", "az kalsın” gibi zarfların kullanılmasına özen gösterilmiştir. 


\begin{tabular}{cc}
\hline Olumluluk & Puan \\
\hline Olumlu & 5 \\
Neredeyse olumlu & 4 \\
Orta derecede olumlu & 3 \\
Biraz olumlu & 2 \\
Olumsuz & 1
\end{tabular}

Tablo 1. Olumluluk Puanları

Sigmoid fonksiyonu $\infty$ ve $-\infty$ arasındaki herhangi bir girdi değerini 0 ve 1 arasındaki bir değere dönüştüren "S" şeklinde bir fonksiyondur (Negnevitsky 2005: 170). Bu fonksiyonun grafiksel gösterimi Şekil 1, matematiksel tanımı ise Eşitlik 1'de verilmiştir.

$$
\mu(x)=\frac{1}{1+e^{-a(x-c)}}
$$

Burada a fonksiyonun eğim parametresi, $\mathrm{x}$ girdi değeri, c ise Sigmoid'in ortasına gelen $\mathrm{x}$ değeridir. $\mathrm{Bu}$ çalışmada girdi değeri (x) uzmanlar tarafindan tümcelere verilen puanların ortalaması olarak alınmıştır. 1 ve 5 arasında olan bu puanların orta değeri 3 olduğu için c parametresi 3 olarak alınmıştır. Fonksiyonun değerini x'in maksimum olduğu durumda $(\mathrm{x}=5)$ 1'e yaklaştıran, minimum $(\mathrm{x}=0)$ olduğunda ise 0 'a yaklaştıran a değeri 2 olarak hesaplanmıştır. Sonuç olarak bu çalışmada a parametresi 2, c parametresi ise 3 olarak alınmıştır.

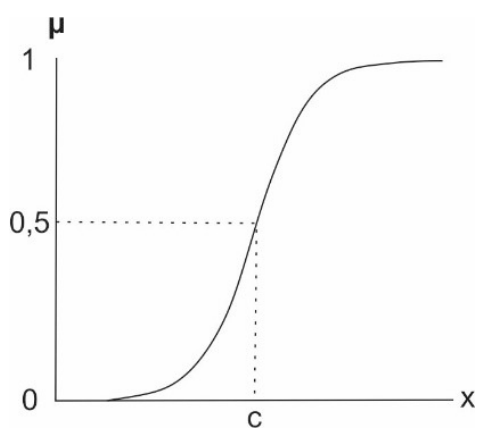

Şekil 1. Sigmoid Fonksiyonu

\section{Bulgular}

Biçimsel dillerde olumluluğun sembolik gösterimini bulanık mantık yaklaşımıyla ele almak ve böylece olumluluk ve olumsuzluk konusundaki belirsizlikleri azaltabilmek amaciyla uzmanlar tarafından incelenen tümceler ve bu tümcelere verilen puanlar şu şekildedir:

\begin{tabular}{lccccccccccccc}
\hline \multirow{2}{*}{ Tümceler } & \multicolumn{1}{c}{ Uzmanlar tarafindan verilen puanlar } & \multicolumn{4}{c}{ Ortalama } \\
\cline { 2 - 10 } & U1 & U2 & U3 & U4 & U5 & U6 & U7 & U8 & U9 & U10 & \\
\hline Çocuk uyudu. & 5 & 5 & 5 & 5 & 5 & 5 & 5 & 5 & 5 & 5 & 5
\end{tabular}


Çocuk uyumadi.

Çocuk uyumak üzere.

Çocuk uyuyacak gibi.

Çocuk neredeyse uyuyacak.

$\begin{array}{llllllllll}1 & 1 & 1 & 1 & 1 & 1 & 1 & 1 & 1 & 1 \\ 4 & 3 & 4 & 2 & 4 & 4 & 4 & 4 & 4 & 4 \\ 3 & 1 & 2 & 4 & 3 & 3 & 3 & 3 & 3 & 2 \\ 4 & 4 & 3 & 3 & 4 & 4 & 4 & 2 & 4 & 3\end{array}$

\begin{tabular}{|c|c|c|c|c|c|c|c|c|c|c|c|}
\hline Yağmur yağmıyor. & 1 & 1 & 1 & 1 & 1 & 1 & 1 & 1 & 1 & 1 & 1 \\
\hline Yağmur yağdı yağacak. & 4 & 4 & 3 & 4 & 2 & 4 & 4 & 2 & 4 & 4 & 3,5 \\
\hline Yağmur yağmak üzere. & 4 & 3 & 3 & 3 & 2 & 4 & 3 & 4 & 3 & 3 & 3,2 \\
\hline Yağmur yağacak gibi. & 3 & 1 & 2 & 2 & 2 & 3 & 3 & 3 & 2 & 2 & 2,3 \\
\hline Yağmur yağıyor. & 5 & 5 & 5 & 5 & 5 & 5 & 5 & 5 & 5 & 5 & 5 \\
\hline Film iyi gibi. & 3 & 3 & 3 & 4 & 4 & 3 & 3 & 2 & 4 & 2 & 3,1 \\
\hline Film iyi. & 5 & 5 & 5 & 5 & 5 & 5 & 5 & 5 & 5 & 5 & 5 \\
\hline Film iyi sayılır. & 4 & 4 & 3 & 3 & 4 & 3 & 4 & 4 & 4 & 4 & 3,7 \\
\hline Film kötü. & 1 & 1 & 1 & 1 & 1 & 1 & 1 & 1 & 1 & 1 & 1 \\
\hline Film fena sayılmaz. & 4 & 2 & 3 & 2 & 3 & 3 & 2 & 3 & 3 & 3 & 2,8 \\
\hline
\end{tabular}

Tablo 2. Örnek Tümceler ve Uzmanlar Tarafından Olumluluk Derecesine Göre Verilen Puanlar

Tablo 2'deki her bir tümce için elde edilen puan ortalamaları kullanılarak söz konusu tümcelerin "olumlu" kümesine olan üyelik dereceleri hesaplanmıştır. Örnek olarak "Çocuk uyumak üzere" tümcesi dikkate alınırsa, bu tümce klasik gösterime göre $\mathrm{P}(\mathrm{x})$ şeklinde gösterilir. Diğer bir ifadeyle 1 üyelik derecesi ile "olumlu" kümesine aittir. Buna karşıın, bu çalış̧ada önerilen yaklaşıma göre söz konusu tümcenin üyelik derecesi Eşitlik 1 ile aşağıdaki şekilde hesaplanır.

$\mu(x)=\frac{1}{1+e^{-a(x-c)}}=\frac{1}{1+e^{-2(3,85-3)}}=0,85$

Dolayısıyla, "Çocuk uyumak üzere" tümcesinin "olumlu" kümesine olan üyelik derecesi 0,85 olarak bulunur. $\mathrm{Bu}$ durumda söz konusu tümce sembolik olarak $\mathrm{P}_{0,85}(\mathrm{x})$ olarak gösterilebilir. Diğer tümcelerin üyelik dereceleri ve sembolik olarak gösterimleri Tablo 3'te sunulmuştur.

\begin{tabular}{lcc}
\hline Tümceler & $\mu_{\text {olumlu }}$ & $\begin{array}{c}\text { Bulanık } \\
\text { sembolik } \\
\text { gösterim }\end{array}$ \\
\hline Çocuk uyudu. & 0,98 & $\mathrm{P}_{0,98}(\mathrm{x})$ \\
Çocuk uyumadi. & 0,02 & $\mathrm{P}_{0,02}(\mathrm{x})$ \\
Çocuk uyumak üzere. & 0,85 & $\mathrm{P}_{0,85}(\mathrm{x})$
\end{tabular}




\begin{tabular}{lcc} 
Çocuk uyuyacak gibi. & 0,27 & $\mathrm{P}_{0,27}(\mathrm{x})$ \\
Çocuk neredeyse uyuyacak. & 0,73 & $\mathrm{P}_{0,73}(\mathrm{x})$ \\
\hline & & \\
\hline Yağmur yağmıyor. & 0,02 & $\mathrm{P}_{0,02}(\mathrm{x})$ \\
Yağmur yağdı yağacak. & 0,73 & $\mathrm{P}_{0,73}(\mathrm{x})$ \\
Yağmur yağmak üzere. & 0,60 & $\mathrm{P}_{0,60}(\mathrm{x})$ \\
Yağmur yağacak gibi. & 0,20 & $\mathrm{P}_{0,20}(\mathrm{x})$ \\
Yağmur yağıyor. & 0,98 & $\mathrm{P}_{0,98}(\mathrm{x})$ \\
\hline & & \\
\hline Film iyi gibi. & 0,55 & $\mathrm{P}_{0,55}(\mathrm{x})$ \\
Film iyi. & 0,98 & $\mathrm{P}_{0,98}(\mathrm{x})$ \\
Film iyi sayıllır. & 0,80 & $\mathrm{P}_{0,80}(\mathrm{x})$ \\
Film kötü. & 0,02 & $\mathrm{P}_{0,02}(\mathrm{x})$ \\
Film fena sayılmaz. & 0,40 & $\mathrm{P}_{0,40}(\mathrm{x})$
\end{tabular}

Tablo 3. Tümcelerin Üyelik Dereceleri ve Bulanık Sembolik Gösterimleri

\section{Sonuçlar}

Bu çalışmada biçimsel dillerdeki mevcut sembolik gösterim için bulanık bir yaklaşım önerilmiştir. Sembolik gösterimin bulanıklaştırılması sürecinde ilk olarak değişik tümceler hazırlanmış ve bu tümceler uzmanlar tarafından olumluluk derecelerine göre puanlandırılmıştır. Tümcelerin "olumlu” kümesine olan üyelik dereceleri ise sigmoid üyelik fonksiyonu ile hesaplanmıştır. $\mathrm{Bu}$ fonksiyonda tümcelere verilen puanların ortalaması girdi değeri olarak alınmıştır. Elde edilen üyelik dereceleri ile bulanık bir sembolik gösterim geliştirilmiştir. Çalışmada önerilen bulanık gösterim şekli bir tümcenin olumlu olma derecesinin anlaşılmasına olanak sağlamaktadır. Örnek olarak "Yağmur yağıyor" ve "Yağmur yağacak gibi" tümceleri dikkate alınacak olursa, her iki tümce de klasik sembolik gösterime göre $\mathrm{P}(\mathrm{x})$ vb. bir şekilde gösterilir. $\mathrm{Bu}$ her iki tümcenin de olumlu olduğu anlamına gelir. Ancak tümcelerin hangi derecede olumlu oldukları anlaşılmamaktadır. Buna karşın, bu çalışmada önerilen bulanık sembolik gösterimde bu iki tümcenin farklı üyelik dereceleri ile olumlu olduğu anlaşılabilir. Bulanık sembolik gösterimde "Yağmur yağıyor" tümcesi $\mathrm{P}_{0,98}(\mathrm{x})$, "Yağmur yağacak gibi" tümcesi ise $\mathrm{P}_{0,20}(\mathrm{x})$ ile ifade edilebilir.

$\mathrm{Bu}$ çalışmada tümcelerin olumluluk derecelerini puanlandırmak için 10 adet uzman görüşü alınmıştır. Ancak bu sayı uzmanların deneyimlerine göre artırılabilir ya da azaltılabilir. Ayrıca çalışma kapsamında önerilen bulanık yaklaşım sadece birkaç tümcede uygulanmıştır. Ancak, tümce örnekleri çoğaltılabilir ve yine uzman görüşleri kullanılarak bir tümceye üyelik derecesi atanabilir. Son olarak, çalışmada sadece P(x) gibi temel gösterim şekilleri dikkate alınmıştır. Biçimsel dillerde değişik ve daha karmaşık gösterim şekilleri olduğu muhakkaktır. Çalışma bu yönde bir ilk adım olarak 
düşünülmeli ve daha sonraki çalışmalarda diğer gösterim şekillerinin de dikkate alınması önerilmektedir.

Olumluluk konusundaki bu tür belirsizlikler, yapay zekânın alt dallarından biri olan doğal dil işleme ve veri madenciliği gibi alanlarda yürütülen duygu analizi çalışmalarında da ortaya çıkabilir. Bu tür çalışmalarda insanların herhangi bir ürünle, projeyle, toplumsal bir olayla veya siyasî bir seçimdeki adaylarla ilgili görüşlerini belirttikleri metinlerin olumluluk durumu analiz edilir. $\mathrm{Bu}$ çalışmada önerilen yaklaşımın, duygu analiziyle incelenen metinlerde karşılaş1labilecek belirsizlikleri azaltmaya yönelik çalışmalara 1şık tutması umut edilmektedir.

\section{Kaynakça}

Börekçi, Muhsine (2003): Türkçe Öğretimi Bakımından Dil Bilgisi Terimi ve Kavram Olarak Olumluluk-Olumsuzluk. TDAY-Belleten. 45,61.

EImas, Çetin (2016): Yapay Zeka Uygulamaları. Yapay Sinir A $\breve{g}$ / Bulanık Mantık/ Sinirsel Bulanık Mantık/ Genel Algoritma. Ankara: Seçkin Yayıncılık (Güncellenmiş 3. Baskı).

Hedstück, Ulrich (2012): Einführung in die Theoretische Informatik: Formale Sprachen und Automatentheorie. München: Oldenbourg Wissenschaftsverlag GmbH.

Hengirmen, Mehmet (2007): Türkçe Dilbilgisi. Ankara: Engin Yayınevi (9. Bask1).

Hodges, Wilfrid (1988): Logic - An Introduction to Elementary Logic. London: Penguin Books.

İmră̆, Özge Sinem (2018): Üretici-Dönüşümsel Dil Bilgisi Işı̆̆ında Almanca, Türkçe ve İngilizcede Olumsuz Önermelerin Dilbilimsel ve Mantıksal Açıdan İncelenmesi, Yayınlanmamış Doktora Tezi, Atatürk Üniversitesi Sosyal Bilimler Enstitüsü, Erzurum.

Karahan, Leyla (2015): Türkçede Söz Dizimi, Ankara: Akçağ Yayınları (2. Baskı).

Negnevitsky, Michael (2005): Artifical Intelligence: A Guide to Intelligent Systems. London: Addison Wesley (Second Edition).

Terricabras, Josep Maria (2015): Language, Fuzzy Logic, Metalogic. Towards the Future of Fuzzy Logic. 21-29.

Toksöz, Derya/Yılmaz Işık (2019): İnce Taneli Zeminler için Önerilen Bulanık Sınıflama Sürecinin Bir Uygulamas1. Pamukkale Üniversitesi Mühendislik Bilimleri Dergisi. 535-544.

Zadeh, Lotfi Aliasker (1965): Fuzzy sets. Information and Control 8(3). 338-353. 